\title{
Anthropometric comparison of cyclists from different events
}

\author{
J.P. Foley, S.R. Bird and J.A. White
}

Department of Movement Studies, Christ Church College, Canterbury and Division of Sport and Leisure Studies, University of Ulster at Jordanstown, Newtownabbey, Northern Ireland

\begin{abstract}
An anthropometric analysis was conducted upon 36 competitive male cyclists (mean age 23.4 years) who had been competing on average for 8.2 years. Cyclists were allocated to one of four groups; sprint, pursuit, road and time trial according to their competitive strengths. The sample included cyclists who were classified as category $1,2,3$ or professional (British Cycling Federation and Professional Cycling Association). The sprint cyclists were significantly shorter and more mesomorphic than the other three groups $(p<0.05)$. The time trialists were the tallest, most ectomorphic group, having the longest legs $(p<0.01)$, the highest leg length/height ratio $(p<0.05)$ and the greatest bitrochanteric width $(p<0.05)$. The pursuit and road cyclists were found to have similar physiques, which were located between those of the sprinters and time trialists. The biomechanical implications of these differences in physique may be related to the high rate of pedal revolutions required by sprinters and the higher gear ratios used by time trialists.
\end{abstract}

Keywords: Anthropometry, cycling

\section{Introduction}

The physique of an athlete is considered to be an important determinant of success in many sports, and in top level sport there would appear to be a tendency for individuals to gravitate towards the event to which they are anthropometrically best suited ${ }^{1-6}$. Investigations into the anthropometry of cyclists are limited. Carter described the somatotype of the typical competitive cyclist as endomorphy: 1.7, mesomorphy: 4.8 , and ectomorphy: $3.1(n=18)^{7}$. However, this was a multiracial group and the description made no distinction between competitors from different events, thus implying a relatively homogenous group.

Carter, as part of the comprehensive study of Olympic athletes directed by De Garay et al. ${ }^{1}$ did subdivide the cyclists into groups, but found little difference in the physiques of competitors from different events. However, certain trends were apparent in these results with a general decrease in mesomorphy and an

Address for correspondence: Dr S.R. Bird, Department of Movement Studies, Christ Church College, North Holmes Road, Canterbury, Kent CT1 1QU

(C) 1989 Butterworth \& Co (Publishers) Ltd

0306-3674/89/010030-04\$03.00 increase in ectomorphy as the duration of the event increased. The average somatotypes were 1.8, 5.2, 2.4 $(\mathrm{n}=14)$ for sprinters, 1.8, 5.1, $2.6(\mathrm{n}=19)$ for pursuiters and 1.8, 4.9, $2.7(n=67)$ for road racers. These trends were also apparent in the work of White et al. ${ }^{8,9}$ where the average somatotype of the sprinters was $2.4,5.1,2.4(\mathrm{n}=8)$ where as that of the road racers was 2.0, 4.3, $2.7(\mathrm{n}=16)$.

These results suggest that, even within the realm of competitive cycling, specific events may require specific physiques as a determinant of success. However, in these studies the road cyclists were assessed as a single group without consideration for individuals with outstanding sprinting ability in road races. These individuals are often recognized as specialist sprinters in road races and indeed many cycling teams and individual cyclists utilize tactics in road races that capitalize upon the sprinting abilities of these individuals. Since it could be argued that the physical demands of sprinting in track and road races are similar it was therefore decided in this study to include such individuals in the sprint rather than the road group.

\section{Materials and methods}

Thirty-six adult male cyclists were studied in the investigation. They included cyclists from two professional teams $(n=12)$, category one $(n=7)$, category two $(n=6)$ and category three $(n=11)$ riders as recognized by the British Cycling Federation (BCF) and Professional Cycling Association (PCA). Subjects were divided into four groups, sprint (track-200 m, road-primes, end of race), pursuit ( $1 \mathrm{~km}-5 \mathrm{~km})$, time trial (10 miles-12 h) and road (no specialist strengths). Each subject was assigned to a group according to their own perception of their competitive strengths and observed performance results. Each of the resulting groups contained a mixture of abilities.

All anthropometric measures were taken by the same investigator prior to the cyclists' training, thus attempting to avoid complicating factors such as dehydration. Skinfold measurements were taken using a Holtain skinfold caliper according to the method described by Katch and Katch ${ }^{10}$. The sites measured were bicep, tricep, suprailiac, abdominal, subscapular and medial calf. A Holtain anthropometer was used to measure bi-iliac width, bitrochanteric width, foot 
Anthropometric comparison of cyclists from different events: J.P. Foley et al.

Table 1. Significant differences in groups demonstrated by Least Significant Difference tests

\begin{tabular}{|c|c|c|c|c|c|c|c|c|c|}
\hline \multirow[b]{2}{*}{ Variable } & \multicolumn{2}{|c|}{$\begin{array}{l}\text { Sprint } \\
(\mathrm{n}=7)\end{array}$} & \multicolumn{2}{|c|}{$\begin{array}{l}\text { Pursuit } \\
(\mathrm{n}=7)\end{array}$} & \multicolumn{2}{|c|}{$\begin{array}{c}\text { Road } \\
(n=16)\end{array}$} & \multicolumn{2}{|c|}{$\begin{array}{c}\text { Time Trial } \\
(\mathrm{n}=6)\end{array}$} & \\
\hline & $\mathbf{x}$ & SE & $\mathbf{x}$ & SE & $\mathrm{x}$ & SE & $\mathbf{x}$ & SE & \\
\hline Height $(\mathrm{cm})$ & 169.2 & 2.5 & 180.6 & 1.7 & 179.2 & 1.8 & 186.3 & 3.0 & ** \\
\hline Weight (kg) & 71.1 & 2.8 & 74.5 & 2.5 & 69.2 & 1.5 & 76.0 & 2.8 & \\
\hline Bi-iliac breadth (mm) & 275 & 5.3 & 284 & 6.9 & 281 & 4.1 & 287 & 7.1 & \\
\hline Bitrochanteric width (mm) & 321 & 5.3 & 329 & 6.1 & 321 & 5.1 & 343 & 8.9 & $*$ \\
\hline Femur length $(\mathrm{mm})$ & 366 & 10.6 & 393 & 4.5 & 398 & 5.2 & 424 & 8.5 & ** \\
\hline Total leg length $(\mathrm{mm})$ & 760 & 19.6 & 827 & 10.2 & 817 & 12.1 & 884 & 17.4 & ** \\
\hline Foot length (mm) & 259 & 5.3 & 279 & 3.7 & 271 & 3.4 & 285 & 6.3 & ** \\
\hline Humerus width (mm) & 70.8 & 1.22 & 72.7 & 1.14 & 70.7 & 1.08 & 71.3 & 1.52 & \\
\hline Femur width (mm) & 99.7 & 2.61 & 96.6 & 2.73 & 100.8 & 0.85 & 100.3 & 2.23 & \\
\hline Ankle width (mm) & 75.8 & 1.2 & 76.4 & 1.6 & 76.4 & 1.0 & 76.5 & 1.8 & \\
\hline Sum of 6 skinfolds (mm) & 42.7 & 6.04 & 41.7 & 4.12 & 41.3 & 3.17 & 52.4 & 8.18 & \\
\hline Endomorphy & 2.2 & 0.20 & 2.2 & 0.24 & 2.1 & 0.21 & 2.9 & 0.54 & \\
\hline Mesomorphy & 6.9 & 0.57 & 5.3 & 0.20 & 4.8 & 0.31 & 3.9 & 0.45 & ** \\
\hline Leg/height ratio $(\times 100)$ & 44.8 & 0.73 & 45.5 & 0.53 & 45.6 & 0.46 & 47.6 & 0.22 & $*$ \\
\hline
\end{tabular}

$* \mathrm{P}<0.05 \quad * * \mathrm{P}<0.01$

length (from the akropodion to the pternion), femur length (from the greater trochanter to the lateral condyle) and lower leg length from the lateral condyle (tibia) to the lateral maleolus (fibula). A Holtain sliding bone width caliper was used to assess the bi-epicondular breadths of the humerus and femur and the width of the ankle (across the lateral malleolus of the fibula and the medial malleolus of the tibia). When measuring bone widths appropriate pressure was applied to the instruments to minimise the influence of subcutaneous tissue. The bicep and calf muscle girths were measured using a steel tape according to the procedure described by Heath and Carter ${ }^{11}$. Height was measured to the nearest centimetre following a deep inspiration ${ }^{7}$ and weight was measured to the nearest half kilogram.

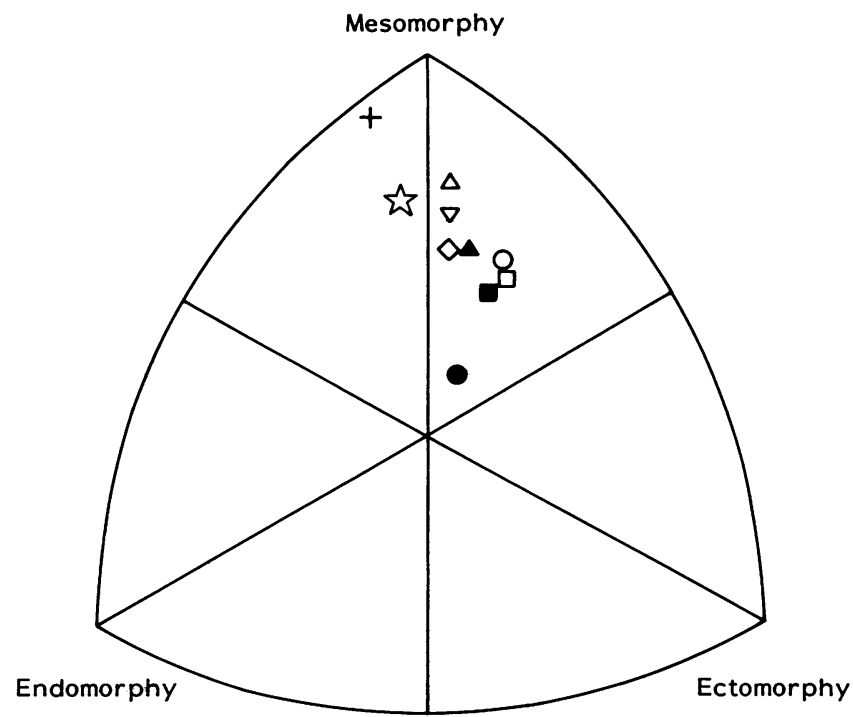

Figure 1. Average somatotypes of cyclists in the present study: sprint $+(n=7)$, pursuit $\boldsymbol{\Delta}(n=7)$, road $\boldsymbol{\square}(n=16)$ and time trial $\bullet(n=6)$.

In other studies:

Carter ${ }^{7}$ - General competitive cyclists $\bigcirc(n=18)$

De Garay et al. ${ }^{1}$ - sprint $\triangle(n=14)$, pursuit $\nabla(n=19)$, road $\diamond$ ( $\mathrm{n}=67$ )

White et al. ${ }^{8.9}$ - sprint ts $(n=8)$, road $\square(n=16)$
From the data obtained, a BBC microcomputer was used to calculate a ponderal index and somatotype rating for each cyclist according to the method described by Heath and Carter ${ }^{11}$. In addition to this, a leg length (measured from the greater trochanter of the femur to the lateral malleolus of the fibula) to height ratio was calculated for each cyclist. The data for the groups of cyclists were compared statistically using Analysis of Variance and Least Significance Difference tests.

\section{Results}

A comparison between the four groups of cyclists (Analysis of Variance) revealed significant differences in ten of the variables. Further analysis using Least Significant Difference tests revealed which groups were significantly different from each other. The data is summarized in Table 1 with the somatotypes presented diagrammatically in Figure 1. The average somatotype for each of the four groups was as follows; sprint 2.2, 6.9, 1.4, pursuit 2.2, 5.3, 2.9, road 2.1, 4.8, 3.5 and time trial 2.9, 3.9, 3.7. Analysis of the mesomorphy ratings showed the Sprint group to be significantly more mesomorphic than the time trial $(P<0.01)$, road $(P<0.01)$ and pursuit $(P<0.05)$ groups. Analysis of the ponderal indexes and ectomorphy ratings showed the sprinters to have a significantly lower $(P<0.01)$ ponderal index and hence ectomorphy rating than any of the other groups while the time trialists had the highest. No significant difference was found in the endomorphy ratings for the four groups or the sum of six skinfolds. However, when the cyclists were regrouped according to the standard categories of the BCF and PCA rather than by event specialism, the professional cyclists had significantly lower skinfold thickness $(\mathrm{P}<0.05)$.

Analysis of the leg length measurements showed the time trial group to have significantly $(P<0.01)$ longer legs than the other three groups. In addition to this, the sprint group had significantly $(P<0.01)$ shorter legs than either the pursuit or road groups. Further analysis of this data revealed the time trial group to have a significantly $(P<0.05)$ higher leg length to height ratio than any of the other groups. 
When the leg length data was analysed further as femur length and lower leg length, the statistically significant differences remained, with the time trialists having the longest bone lengths and the sprinters the shortest in both the femur and lower leg. No significant differences were found between the pursuit and road groups for any of the leg measurements. Analysis of foot length revealed the sprinters to have significantly $(P<0.01)$ shorter feet than any of the other groups, whilst the time trialists had the longest. The analysis of ankle, femur and humerus bi-epicondular widths revealed no significant differences between groups. The time trialists had significantly wider bitrochanteric breadths than either the sprint or road groups $(P<0.05)$. Since the time trialists were also the tallest group, this difference could be associated with general skeletal size. Analysis of bi-iliac breadth showed no significant difference $(P>0.1)$ between the four groups.

\section{Discussion}

The results showed similar trends to those exhibited in the work of De Garay et al. ${ }^{1}$ and White et al. ${ }^{8,9}$ with the sprinters having the highest mesomorphy and lowest ectomorphy ratings. The general decrease in mesomorphy and increase in ectomorphy as the duration of the event increased was also in agreement with the results of these previous studies. The statistically significant differences in physique observed in this study but not in previous investigations may be due to the reclassification of specialist road race sprinters as sprinters rather than road racers.

The high mesomorphy ratings of the sprinters would support the suggestions of White et al. ${ }^{12}$ who stated that there was a high correlation between mesomorphy and body strength. Since strength is a major contributer in the generation of power, the high mesomorphy of sprinters might be expected. Since mesomorphy is determined by considering the height of the individual, the sprinters high mesomorphy ratings may be accentuated by their being the shortest group. Conversely, the relatively low mesomorphy ratings of the time trial group may be accentuated by their relative tallness, resulting in a more ectomorphic physique.

The finding that the professional cyclists had the lowest sum of six skinfolds supports the view of the importance of a low percentage body fat as a determinant of success in sports where the body has to be propelled over a distance. Indeed, a relatively low endomorphy rating was a notable characteristic of all the top cyclists regardless of their specialist strengths, whilst no other significant anthropometric differences were found between cyclists of different standards. The significant differences in leg length may be related to the nature of the different events. Time Trial racing produces specialists who utilize gear ratios far higher than those used by riders in other events. It may therefore be suggested that a longer leg length could convey mechanical advantages such as enabling the use of a longer crank arm. Conversely, the ability to sprint in cycling requires the rider to generate great amounts of power as quickly as possible. This will largely be deter- mined by the individual's capacity to utilize the relevant energy systems.

However, the cyclist's leg length may also be a significant factor. Indeed, the significantly shorter bone lengths of the sprinters would appear to support the comments of $\AA$ strand and Rodahl ${ }^{13}$ who suggested that athletes with shorter limbs could tolerate a greater quickness of movement. Shorter legs may therefore convey an advantage when sprinting where extremely high pedal revolutions are required.

The significant differences in foot length and bitrochanteric breadth may be expected in the light of other measurements since they are likely to be related to overall skeletal development and be relative to lower limb lengths. However, the analysis of bi-iliac breadth which showed no significant difference between the four groups would seem to contradict the findings of Carter who stated that road cyclists had wider bi-iliac breadths than track cyclists ${ }^{7}$. However, this contradiction may be due to the track cyclists in Carter's study including both specialist track sprinters and pursuit riders and/or the multiracial composition of the sample, thus producing a somewhat heterogeneous group, whereas in this study the track sprinters and pursuit riders were assessed as separate groups. In addition to this, the classification of road sprinters into the sprint group rather than the road group could also account for the conflicting conclusions. The analysis of ankle, femur and humerus bi-epicondular widths revealed no significant differences between groups. Therefore, these results would agree with the findings of Tanner ${ }^{6}$ in his work on track and field athletes where he concluded that the relative widths of long bones had no significant influence on performance.

\section{Conclusions}

A number of distinct significant musculoskeletal differences were detected between the four groups of cyclists. The sprinters were the shortest and the most mesomorphic. The time trialists were the tallest, most ectomorphic, had the longest legs and had the highest leg length to height ratios. They also had significantly wider bitrochanteric breadths. However, because of the interrelated nature of skeletal growth and development in all parts of the body it is difficult to suggest which anthropometric characteristics are important in determining success in specific events. However, it may be speculated that the shorter limb lengths and higher mesomorphy ratings of the sprinters are an advantage in generating power and obtaining a high rate of pedal revolutions. Conversely, longer limbs may convey an advantage in time trialing where higher gear ratios tend to be used.

Therefore it may be suggested that since the different forms of competitive cycling place different demands upon the body, each form of cycling may require a different optimum physique rather than a general cyclist's physique for all types of competition.

\section{Acknowledgements}

The authors would like to thank all subjects especially Team Raleigh Banana and Team Everready-Ammoco. 


\section{References}

1 De Garay, A.L., Levine, L. and Carter, J.E.L. 'Genetic and anthropological studies of Olympic athletes', Academic Press, New York, 1974

2 Hirata, K. Physique and age of Tokyo Olympic champions J Sports Med Phys Fitness 1966, 6, 207-222

3 Housh, T.J., Thorland, W.G., Johnson, G.O. and Tharp, G.D. Body build and composition variables as discriminators of sports participation of elite adolescent male athletes J Sports Med Phys Fitness 1984, 24(3), 169-174

4 Reilly, T. and Hardiker, R. Somatotype and injuries in adult student rugby football J Sports Med 1981, 21, 186-191

5 Singh, S.P. and Sidhu, S. Physique and morphology of Jat-Sikh cyclists of the Punjab J Sports Med Phys Fitness 1982, 22, 185-190

6 Tanner, J.M. 'The Physique of the Olympic Athlete', Allen and Unwin, London, 1964

7 Carter, J.E.L. (Ed.) 'Physical structure of Olympic athletes' Part 1. The Montreal Olympic Games Anthropological Project. Medicine and Sport 16. Basel: S. Karger, Basel, 1982
8 White, J.A., Quinn, G. Al-Dawalibi, M. and Mulhall, J. Seasonal changes in cyclists' performance-part 1 . The British Olympic road race squad Br J Sports Med 1982, 16(1), 4-12

9 White, J.A., Quinn, G. Al-Dawalibi, M. and Mulhall, J. Seasonal changes in cyclists' performance-part 2 . The British Olympic track squad Br J Sports Med 1982, 16(1), 13-21

10 Katch, F. and Katch, V. Measurement and prediction errors in body composition assessment and the search for the perfect prediction equation Res Quart Exer and Sp 1980, 51(1), 249-260

11 Heath, B.H. and Carter, J.E.L. A modified somatotype method Am J Anthrop 1967, 27, 57-74

12 White, J.A., Quinn, G. Al-Dawalibi, M. and Mulhall, J. A technical report submitted to the British Cycling Federation with special reference to the evaluation of the road squad's winter training programme (Nov 1978Feb 1979)

13 Åstrand, P.O. and Rodahl, K. 'Textbook of Work Physiology' McGraw-Hill, New York, 1977

\title{
Edinburgh Post-Graduate Board For Medicine
}

\author{
Sports Medicine Course \\ 11/15 September 1989
}

This intensive practical course has been designed primarily for general practitioners actively involved in sports medicine. A limited number of places will also be available for qualified physiotherapists, coaches or doctors in other branches of medicine. The venue for this course will be Moray House College of Education, Cramond Campus, Cramond Road North, Edinburgh.

Course Fee $£ 120.00$-subject to review (Section 63 approval for general practitioners but $€ 30.00$ fee in view of specialized nature of course).

Applications should be made to:

The Post-Graduate Dean

Edinburgh Post-Graduate Board for Medicine

Pfizer Foundation

Hill Square

Edinburgh

EH8 9DR 